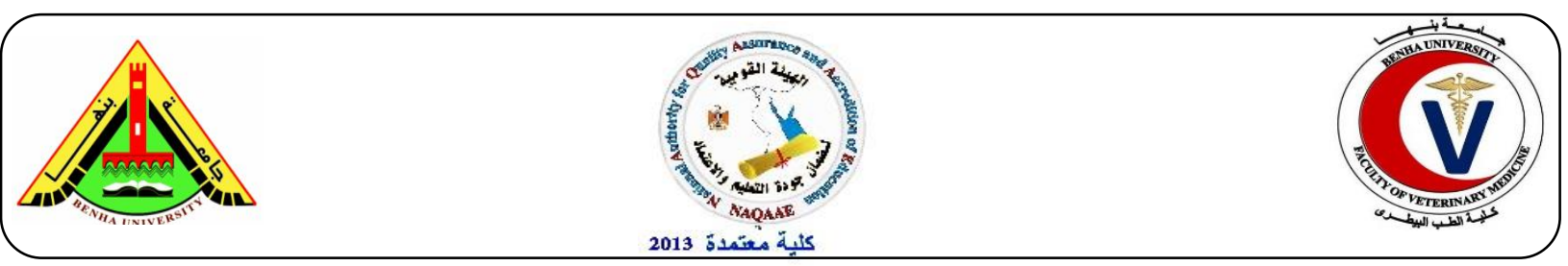

\title{
Effect of tramadol drug on some biochemical and immunological parameters in albino male rats; evaluation of possible reversal following its withdrawal
}

\author{
Samy A. Hussein ${ }^{1}$, Samir A. Abdel Aal ${ }^{2}$, Hany K. Ismail ${ }^{1}$ \\ ${ }^{1}$ Department of Biochemistry, Faculty of Veterinary Medicine, Benha University, ${ }^{2}$ Department of \\ Animal, Poultry and Environmental Hygiene, Faculty of Veterinary Medicine, Benha University
}

\begin{abstract}
A B S T R A C T
The purpose of this study was to evaluate the effect of repeated tramadol drug administration on some biochemical and immunological parameters in rats. One hundred male albino rats were divided into three main groups. Group I (control): contains twenty rats administered saline solution. Group II (therapeutic dose group): forty rats received a daily oral dose of tramadol $\mathrm{Hcl}$ suspended in saline solution equal to $22.5 \mathrm{mg} / \mathrm{kg} / \mathrm{day}$ for nine weeks. Ten rats of second group were left two weeks more without any additional treatment as a recovery period. Group III (over dose group): forty rats received oral dose of tramadol $\mathrm{Hcl}$ suspended in saline solution at doses of 30,60 and $90 \mathrm{mg} / \mathrm{kg} / \mathrm{day}$ on the first, second and third three weeks of the study, respectively for nine weeks. Ten rats of third group were left for two weeks more without any additional treatment as a recovery period. The obtained results showed significant increase in serum marker (Urea, creatinine, sialic acid, TNF- $\alpha$ and IL-1 $\beta$ ) levels, and brain tissue (NF-KB and MPO) levels in both tramadol therapeutic and overdose groups towards its normal ranges. However, brain tissue antioxidant parameters (GPX and GSH) levels and liver tissue marker cyp2E1were markedly decreased. These results showed that, chronic tramadol administration induced kidney dysfunction, brain injury, oxidative and inflammatory stress in rats as well as degenerating endogenous antioxidant defense system mechanisms. These findings are of importance to be considered in the patients who use tramadol as a pain killer especially in the long term condition.
\end{abstract}

Keywords: Tramadol, Oxidative stress, Neurotoxicity.

(http://www.bvmj.bu.edu.eg)

(bvmj, 33(2): 418-429, DECEMBER, 2017

\section{INTRODUCTION}

Addiction is an increasing social and health problem worldwide despite all efforts to prevent and control it. Analgesics are among the most popular drugs which are being abused (Rafati et al., 2006). The abuse liability of naturally occurring opiates (e.g., morphine, codeine) and synthetic opioids (e.g. Tramadol, heroin, oxycodone, and buprenorphine) are well known (Moratti et al., 2010) and (Meyer et al., 2014). Tramadol is a centrally acting opioid analgesic which is mainly used for the treatment of moderate to severe pain (Nossaman et al., 2010). It has a dosedependent analgesic efficacy that lies between that of codeine and morphine, with a parenteral potency comparable to that of pethidine, i.e; about $10-20 \%$ of the standard morphine (Wilder-Smith et al., 1999; Pang et al., 2003). Tramadol has dual mode of action. Its analgesic efficacy is attributed to its partial affinity for the mu- opiate receptor and its inhibition of norepinephrine and serotonin reuptake (Shadnia et al., 2008).

The central role of liver and kidney in drug metabolism predisposes them to toxic injury. Tramadol in the liver is converted to O-desmethyl-tramadol by cytochrome $\mathrm{P}$ 450 which itself is an active substance and is two to four times more potent than 
tramadol. Further, biotransformation results in inactive metabolites, which are excreted through kidneys (Dickman, 2007). Persistent tramadol administration might lead to the accumulation of toxic metabolites in the body, increase the risk for its toxic kinetics effects and/or lower the clearance of tramadol, thus increasing its potential for toxicity (Shadnia et al., 2008). The most frequent adverse effects of tramadol hydrochloride include constipation, dizziness, nausea, somnolence, headache and vomiting (Stitik et al., 2006). The other dosage toxicity symptoms include central nervous system and respiratory depression LethargyComa, cardiac arrest and death (Feldmann, 2006). Neurotoxicity of tramadol has been reported in patients receiving tramadol both at the recommended dosage and the high dosage ranges in animal and human studies (Bekjarovski et al., 2012). The neurotoxicity of tramadol commonly manifests as generalized tonic-clonic seizures. Chronic use of tramadol in increasing doses causes neuronal degeneration in the rat brain, which probably contributes to cerebral dysfunction (Atici et al., 2005). Tramadol also alters brain neurotransmitter levels (Bloms-Funke et al., 2011).

Long- term administration of tramadol for management of pain, as well as its use as an acceptable alternative in persons with drug- seeking behavior is controversial (Drugs and Therapy Bulletin, 2002). Also, long- term effects of tramadol at cellular level, are not clearly understood (Atici, et al., 2005).

This study was designed to investigate deleterious effect of tramadol administration in adult male rats through investigation of renal functions, biomarkers of oxidative DNA damage, oxidative and inflammatory stress and enzymatic antioxidant status.

\section{MATERIAL AND METHODS}

\subsection{Experimental animals}

One hundred white male albino rats of weighing $180-200 \mathrm{~g}$ were used in this study. Rats were housed in separated metal cages and kept at constant environmental and nutritional conditions throughout the period of experiment. The rats were fed on constant ration and fresh, clean drinking water was supplied ad-labium. All rats were acclimatized for minimum period of two weeks prior to the beginning of study.

\subsection{Drug}

Tamol $^{\circledR}$ (Tramadol $\mathrm{HCl}$ ), $225 \mathrm{mg}$ tablets, will be obtained from Alkan- pharm, Egypt.

\subsection{Experimental design}

After acclimatization to the laboratory conditions, rats were randomly divided into three groups placed in individual cages and classified as follow:

Group I (control normal group): Twenty normal non- medicated rats served as control for all experimental groups received oral doses of saline solution for nine weeks.

Group II (Therapeutic dose group): forty Rats in group II received a daily oral dose of tramadol $\mathrm{Hcl}$ suspended in saline solution equal to $22.5 \mathrm{mg} / \mathrm{kg} / \mathrm{day}$ for nine weeks. Ten rats were left two weeks more without any additional treatment as a recovery period.

Group III (Over dose group): forty rats in group III received oral dose of tramadol $\mathrm{Hcl}$ suspended in saline solution at doses of 30,60 and $90 \mathrm{mg} / \mathrm{kg} /$ day on the first, second and third three weeks of the study, respectively. Ten rats were left two weeks more without any additional treatment as a recovery period.

\subsection{Sampling \\ 2.4.1. Blood samples}

About $2 \mathrm{ml}$ of blood samples were collected by ocular vein puncture from rats in all groups after nine and eleven weeks (for recovery period) from the onset of the experiment in dry, clean tubes and allowed to clot for30 minutes and serum was 
separated by centrifugation at 3000 r.p.m for 15 minute. All sera were analyzed for determination of the following parameters: urea, creatinine, sialic acid, interleukin- $1 \beta$ (IL-1 $\beta$ ) and tumor necrosis factor-alpha $(\mathrm{TNF}-\alpha)$

\subsubsection{Tissue samples (brain and liver)}

a- brain tissue for biochemical analysis:

About $0.5 \mathrm{~g}$ of brain tissue specimen was taken two times after had been sacrificed at nine and eleven weeks from the onset of the experiment.

Preparation of brain tissue homogenate: Briefly, brain tissues were cut, weighed and minced into small pieces, homogenized with a glass homogenizer in 9 volume of ice-cold $0.05 \mathrm{mM}$ potassium phosphate buffer ( $\mathrm{pH} 7.4)$ to make $10 \%$ homogenates. Then the resultant supernatant was used for the determination of the following parameters: nuclear factor kappa B (NF-kB), myeloperoxidase (MPO), glutathione peroxidase (GPX), reduced glutathione, $(\mathrm{GSH})$ in brain tissue.

b- Liver tissue for molecular analysis:

After finishing blood samples, rats of each group were sacrificed and the abdomen was opened carefully and the liver was quickly removed, and the liver samples were sacrificed using highly sterilized scissors $\left(180^{\circ} \mathrm{Cfor} 6\right.$ hours) to avoid RNA degradation by RNases and latex gloves wearied to minimize RNase contamination. All liver samples were used for determination of gene expression of Cytochrome P450 2E1 (CYP2E1).

\subsection{Biochemical analysis}

Serum urea, creatinine, sialic acid, interleukin-1 $\beta$ (IL-1 $\beta$ ) tumor necrosis factor-alpha (TNF- $\alpha)$ were determined according to the method described by Kaplan et al., (2003), Tietz, (1995), rats sialic acid Elisa kit (Cat.No.CSB-E09605h, Cusabio, Biotech Co, Wuhan, China), rats IL-1 $\beta$ ELISA (RayBiotech, Inc Company, Cat\#: ELR-IL1 $\beta$ ) and Beyaert and Fiers
(1998). Moreover, brain tissue NF-KB, MPO, glutathione peroxidase, reduced glutathione were determined according to the method described by rats NF-kB Elisa Kit (Cat.No.MBS814487), rats MPO ELISA kit (Kamiya Biomedical Company, Cat. No. KT-60345), Gross et al. (1967), Moron et al. (1979), gene expression of CYP 450 2E1 in rat liver tissue was determined according to the method described by (Meadus 2003).

\subsection{Statistical analysis}

The results were expressed as mean $\pm \mathrm{SE}$ and statistical significance was evaluated by one-way ANOVA using (SPSS IBM 1983, version10. New York, NY, USA: IBM Incorporation) program followed by the post hoc test, least significant difference (LSD). Values were considered statistically significant when $\mathrm{P}<0.05$.

\section{RESULTS}

The obtained results demonstrated in (Table 1) exhibited that, after 9 weeks of tramadol exposure there was a significant increase in serum urea concentration in both tramadol therapeutic and overdose groups when compared with normal control group, while there was a significant decrease in brain tissue GPX and GSH concentrations in both tramadol therapeutic and overdose groups when compared with normal control group. On the other hand there was a non-significant increase in creatinine concentration in the therapeutic dose group when compared with the normal control group.After 2 weeks without any additional treatment as a recovery period there was a non significant decrease in serum creatinine concentration in both tramadol withdrawal therapeutic dose and tramadol withdrawal overdose groups when compared with therapeutic dose and overdose groups respectively, while there was a significant decrease in serum creatinine concentration in tramadol withdrawal therapeutic dose group when compared with therapeutic dose group. On the other hand there was a 
significant increase in brain tissue GSH concentration in both tramadol withdrawal therapeutic and withdrawal overdose groups when compared with therapeutic and overdose groups respectively. While there was a non significant increase in brain tissue GPX concentration in both tramadol withdrawal therapeutic and withdrawal overdose groups when compared with therapeutic and overdose groups respectively.

The obtained results demonstrated in (Table 2) exhibited that, after 9 weeks of tramadol exposure there was a significant increase in serum sialic acid, IL-1 $\beta$ and TNF- $\alpha$ concentrations accompanied with significant increase in brain tissue NF-kB, MPO concentrations in both tramadol therapeutic and overdose groups when compared with normal control group, while there was a non-significant increase in sialic acid, TNF- $\alpha, \mathrm{NF}-\mathrm{kB}$ and MPO concentrations in the therapeutic dose group when compared with the normal control group.

After 2 weeks without any additional treatment as a recovery period there was a non significant decrease in serum sialic acid and TNF- $\alpha$ concentrations accompanied with non significant decrease in brain tissue NF-kB and MPO concentrations in both tramadol withdrawal therapeutic dose and tramadol withdrawal overdose groups when compared with therapeutic dose and overdose groups respectively, while there was a significant decrease in serum and sialic acid concentration in tramadol withdrawal therapeutic dose group when compared with therapeutic dose group, also a significant decrease in serum IL- $1 \beta$ concentration in both tramadol withdrawal therapeutic group and tramadol withdrawal over dose group when compared with therapeutic group and over dose group respectively.

The obtained results demonstrated in (Table 2) exhibited that, after 9 weeks of tramadol exposure there was a significant decrease in brain tissue cyp 450 2E1 levels in both tramadol therapeutic and overdose groups when compared with normal control group.

After 2 weeks without any additional treatment as a recovery period there was a significant increase in cyp 450 2E1 levels in both tramadol withdrawal therapeutic and withdrawal overdose groups when compared with therapeutic and overdose groups respectively.

Table (1) Tramadol $\mathrm{HCl}$ administration at both the therapeutic dosage and the high dosage ranges on serum urea and creatinine and brain tissue GPX and GSH and liver tissue Cyp 2E1 in rats

\begin{tabular}{cccccccccccc}
\hline & \multicolumn{2}{c}{ Urea (U/L) } & \multicolumn{2}{c}{ Creatinin (U/L) } & \multicolumn{2}{c}{ GPX (ng/g.tit) } & \multicolumn{2}{c}{ GSH (ng/g.tit) } & \multicolumn{2}{c}{ Cyp 2E1 } \\
\cline { 2 - 11 } Rat groups & 9 & 2 & 9 & 2 & 9 & 2 & 9 & 2 & 9 & 2 \\
& WT & WW & WT & WW & WT & WW & WT & WW & WT & WW \\
\hline Group I: & & & & & & & & & & \\
(Normal & $33.66 \pm 1.09^{\mathrm{b}}$ & $1.03 \pm 0.03^{\mathrm{a}, \mathrm{b}}$ & $31.24 \pm 2.22^{\mathrm{a}}$ & $8.68 \pm 0.82^{\mathrm{a}}$ & & $1.00 \pm 0.04^{\mathrm{a}}$ \\
control group) & & & & & & & & & & \\
Group: П & 43.5 & 31.34 & 1.17 & 0.94 & 20.86 & 26.21 & 4.7 & 7.57 & 0.41 & 0.59 \\
(therapeutic & \pm & \pm & \pm & \pm & \pm & \pm & \pm & \pm & \pm & \pm \\
dose group) & $3.7^{\mathrm{a}}$ & $1.99^{\mathrm{b}}$ & $0.07^{\mathrm{a}}$ & $0.05^{\mathrm{b}}$ & $1.33^{\mathrm{b}}$ & $2.66^{\mathrm{a}, \mathrm{b}}$ & $0.04^{\mathrm{b}, \mathrm{c}}$ & $0.4^{\mathrm{a}}$ & $0.07^{\mathrm{c}}$ & $0.05^{\mathrm{b}}$ \\
Group III: & 44.33 & 35.7 & 1.15 & 1.03 & 20.49 & 23.27 & 4.04 & 5.93 & 0.04 & 0.37 \\
(over dose & \pm & \pm & \pm & \pm & \pm & \pm & \pm & \pm & \pm & \pm \\
group) & $3.37^{\mathrm{a}}$ & $2.11^{\mathrm{b}}$ & $0.06^{\mathrm{a}}$ & $0.04^{\mathrm{a}, \mathrm{b}}$ & $1.03^{\mathrm{b}}$ & $1.09^{\mathrm{b}}$ & $0.55^{\mathrm{c}}$ & $0.51^{\mathrm{b}}$ & $0.01^{\mathrm{d}}$ & $0.03^{\mathrm{c}}$ \\
\hline
\end{tabular}

WT (week treatment) WW (week withdrawal) Data are presented as (Mean \pm S.E). S.E = Standard error. Mean values with different superscript letters in the same column are significantly different at $(\mathrm{P} \leq 0.05)$. 
Table (2) Tramadol $\mathrm{HCl}$ administration at both the therapeutic dosage and the high dosage ranges on serum Sialic acid, TNF- $\alpha$, IL-1B and brain tissue NF Kb and MPO in rats

\begin{tabular}{|c|c|c|c|c|c|c|c|c|c|c|}
\hline \multirow{2}{*}{ Rat groups } & \multicolumn{2}{|c|}{$\begin{array}{l}\text { Sialic acid } \\
\text { (ng/ml.tit) }\end{array}$} & \multicolumn{2}{|c|}{$\begin{array}{c}\text { TNF- } \alpha \\
\text { (pg/ml.tit) }\end{array}$} & \multicolumn{2}{|c|}{$\begin{array}{c}\text { IL-1B } \\
\text { (pg/ml.tit) }\end{array}$} & \multicolumn{2}{|c|}{$\begin{array}{l}\text { NF-Kb } \\
\text { (ng/g.tit) }\end{array}$} & \multicolumn{2}{|c|}{$\begin{array}{c}\text { MPO } \\
\text { (ng/g.tit) }\end{array}$} \\
\hline & $\begin{array}{c}9 \\
\text { WT }\end{array}$ & $\begin{array}{c}2 \\
\mathrm{WW}\end{array}$ & $\begin{array}{c}9 \\
\text { WT }\end{array}$ & $\begin{array}{c}2 \\
\mathrm{WW}\end{array}$ & $\begin{array}{c}9 \\
\text { WT }\end{array}$ & $\begin{array}{c}2 \\
\mathrm{WW}\end{array}$ & $\begin{array}{c}9 \\
\text { WT }\end{array}$ & $\begin{array}{c}2 \\
\mathrm{WW}\end{array}$ & $\begin{array}{c}9 \\
\text { WT }\end{array}$ & $\begin{array}{c}2 \\
\mathrm{WW}\end{array}$ \\
\hline $\begin{array}{c}\text { Group I: } \\
\text { (Normal } \\
\text { control group) }\end{array}$ & \multicolumn{2}{|c|}{$2.71 \pm 0.15^{\mathrm{b}, \mathrm{c}}$} & \multicolumn{2}{|c|}{$17.89 \pm 2.84^{\mathrm{b}, \mathrm{c}}$} & \multicolumn{2}{|c|}{$4.16 \pm 0.33^{\mathrm{c}}$} & \multicolumn{2}{|c|}{$0.36 \pm 0.07^{b}$} & \multicolumn{2}{|c|}{$4.88 \pm 0.52^{\mathrm{b}}$} \\
\hline $\begin{array}{l}\text { Group: } \Pi \\
\text { (therapeutic } \\
\text { dose group) }\end{array}$ & $\begin{array}{c}3.35 \\
\pm \\
0.32^{\mathrm{a}, \mathrm{b}}\end{array}$ & $\begin{array}{c}2.44 \\
\pm \\
0.24^{\mathrm{c}}\end{array}$ & $\begin{array}{l}20.51 \\
\pm \\
1.44^{\mathrm{bc}}\end{array}$ & $\begin{array}{l}15.96 \\
\pm \\
1.76^{\mathrm{c}}\end{array}$ & $\begin{array}{c}7.30 \\
\pm \\
0.33^{\mathrm{a}}\end{array}$ & $\begin{array}{c}5.63 \\
\pm \\
0.14^{\mathrm{b}}\end{array}$ & $\begin{array}{c}0.48 \\
\pm \\
0.05^{\mathrm{b}}\end{array}$ & $\begin{array}{c}0.45 \\
\pm \\
0.05^{\mathrm{b}}\end{array}$ & $\begin{array}{c}6.7 \\
\pm \\
0.36^{\mathrm{b}}\end{array}$ & $\begin{array}{c}6.06 \\
\pm \\
0.46^{\mathrm{b}}\end{array}$ \\
\hline $\begin{array}{l}\text { Group III: } \\
\text { (over dose } \\
\text { group) }\end{array}$ & $\begin{array}{c}3.53 \\
\pm \\
0.1^{\mathrm{a}}\end{array}$ & $\begin{array}{c}3.23 \\
\pm \\
0.13^{\mathrm{a}, \mathrm{b}}\end{array}$ & $\begin{array}{c}32.21 \\
\pm \\
2.66^{\mathrm{a}}\end{array}$ & $\begin{array}{c}25.79 \\
\pm \\
3.32^{\mathrm{a}, \mathrm{b}}\end{array}$ & $\begin{array}{c}5.21 \\
\pm \\
0.36^{\mathrm{b}}\end{array}$ & $\begin{array}{c}4.88 \\
\pm \\
0.27^{\mathrm{bc}}\end{array}$ & $\begin{array}{c}0.74 \\
\pm \\
0.04^{\mathrm{a}}\end{array}$ & $\begin{array}{c}0.71 \\
\pm \\
0.02^{\mathrm{a}}\end{array}$ & $\begin{array}{c}11.3 \\
\pm \\
0.45^{\mathrm{a}}\end{array}$ & $\begin{array}{c}9.41 \\
\pm \\
1.14^{\mathrm{a}}\end{array}$ \\
\hline
\end{tabular}

WT (week treatment) WW (week withdrawal) Data are presented as (Mean \pm S.E). S.E $=$ Standard error. Mean values with different superscript letters in the same column are significantly different at $(\mathrm{P} \leq 0.05)$

\section{DISCUSSION}

The obtained results showed that, after 9 weeks of tramadol exposure there was a significant increase in serum urea concentration in both tramadol therapeutic and overdose groups when compared with normal control group, while there was a non-significant increase in creatinine concentration both tramadol therapeutic and overdose groups when compared with normal control group. These results came in accordance with the recorded data of Atici et al., (2005) who reported that, Serum urea nitrogen concentration and creatinine levels were significantly higher in tramadol rats group compared to the control group. Also, Elwy and Tabl, (2014) revealed that, administration of tramadol for one month induced significant increase in serum urea and creatinine concentrations as compared to control rats. Moreover, Hafez et al., (2015) recorded that, serum blood urea nitrogen concentration increased significantly in tramadol exposure rats when compared with normal group indicating toxicity induced by tramadol administration was detected while there was no significant difference detected in serum creatinine. Furthermore, Youssef and Zidan (2016) demonstrated that, serum urea and creatinine concentrations were highly significant increase in tramadol treated rats group when compared with normal group. Urea is the principal end product of protein catabolism an accelerated amino acid deamination for gluconeogenesis is probably an acceptable postulate to interpret the increased level of urea. The increment in blood urea might be also due to the destruction of RBCs during the treatment. The presence of some toxic compounds might increase blood urea (Kabel and Van Puijenbroek, 2005). In the present investigation, the recorded data indicated increases in both urea and creatinine levels in rats received tramadol. This could be considered as an evidence of renal damage, arise in blood damaging of nephrons function and impaired renal function (Aldalou et al., 2014). On the other hand, tramadol withdrawal of therapeutic dose and overdose in male rats causes a significant decrease in serum urea and creatinin concentrations when compared with therapeutic dose and overdose groups. These results may be 
indicated the improvement of kidney function and returned renal filtration to normal case. The obtained results revealed that, there was a significant increase in serum sialic acid concentrations were significantly increased in tramadol overdose group while there was a nonsignificant increase in the therapeutic dose group when compared with the normal control group. Meanwhile, a significant decrease in serum sialic acid concentrations was observed in tramadol withdrawal therapeutic dose group when compared with therapeutic dose while there was a non-significant decrease in withdrawal overdose group when compared with overdose group. Sialic acid (SA) is the generic term given to a family of acetylated derivatives of neuraminic acid which occur mainly at terminal positions of glycoprotein and glycolipid oligosaccharide side-chains. Several biological functions have been suggested for SA, such as stabilizing the conformation of glycoproteins and cellular membranes, assisting in cell-cell recognition and interaction, contributing to membrane transport, providing binding sites for ligands for the membrane receptor functions, and affecting the function, stability and survival of glycoproteins in blood circulation (Sumangala et al., 1998). The increase of SA concentration in tramadol treated rats may be due to defense mechanisms of the body as a result of damage to the liver and brain tissue. Sialic acids are known to exist in animals and occupy the terminal position of many glycoproteins. An earlier study suggested that $\mathrm{OH}^{-}$reacted with a wide range of sugars including mannitol, fructose, galactose and sialic acid (Anbar and Neta, 1967). Also, Eguchi et al., (2005) indicated that, the glycosidic linkage of sialic acid is a potential target for superoxide and other related ROS. Furthermore, Ogasawara et al., (2007) recorded that, mucin acts as a sacrificial scavenger for $(-\mathrm{OH})$ and its protective function is exerted by the direct reaction with its sialic acids.
The recorded data revealed that, there was a significant increase in serum IL-1B, TNF- $\alpha$ and brain tissue NF-KB concentrations in tramadol therapeutic and overdose groups while there was a nonsignificant increase in serum TNF- $\alpha$ and brain tissue NF-KB concentrations in the therapeutic dose group compared with the normal control group. These results are nearly similar to those recorded by Elwy and Tabl, (2014) who revealed that, administration of tramadol for 30 days induced non-significant increase in serum IL- 1B concentration as compared to control rats. In these days, tramadol are becoming increasingly popular in postoperative patient controlled analgesia. Their immuno-modulatory effects are still unclear. Nuclear factor kappa B is an important transcription factor, which transactivates hundreds of immune-related genes and has been named the "central mediator of immune response" (Pahl, 1999). Nuclear factor kappa B is an important transcription factor, which transactivates hundreds of immune-related genes and has been named the "central mediator of immune response" (Pahl, 1999). Many authors reported an enhancing effect of tramadol on the immune activity, both in vitro and in vivo. For example, after subcutaneous administration of tramadol significantly enhanced nature killer activity, IL-2 production and splenocyte proliferation in mice (Sacerdote et al., 1997). In postoperative patients who were given tramadol analgesia after abdominal surgery, the nature killer cell activity was also enhanced (Sacerdote et al., 2000). Many research groups focused on the effects of different medicines on NF-kB with its signaling pathway so as to evaluate the immunological effect of the drugs (Yamamoto and Gaynor, 2001).

Tumor necrosis factor-alpha is considered to be one of the principal mediators in proinflammatory processes that involve necrosis, apoptosis and proliferation (DeLeo et al., 2000; Kawasaki et al., 
2008). It is produced essentially by macrophages and T-lymphocytes in response to damaged or stressed tissue, and it may therefore serve as a systemic marker for tissue injury. For instance, complications found in inflammatory and autoimmune diseases are often accompanied by increased serum levels. In case of increased levels, a systemic inflammatory reaction leading to septic shock might occur. However, if TNF- $\alpha$ is present in low quantities it would generate a process responsible for local inflammatory symptoms, depending on the damaged structure (Li et al., (2009); Lindenlaub and Sommer, (2003); Liu et al., (2002)).

The interleukin-1 beta and TNF- $\alpha$ are major pro-inflammatory cytokines, playing important role in production of acute inflammation (Konturek et al., 2000). This acute inflammation is accompanied by neutrophils infiltration. Neutrophils produce superoxide radical anion $\left(\mathrm{O} 2^{\circ}\right)$, which belongs to group of ROS (Brzozowski et al., 2001). ROS at relatively low concentrations can modulate inflammation via activation of NF-kB pathway (Hayden and Ghosh, 2011). Also, Dey and Cederbaum, (2006) reported that, the free radicals activate NF-kB, leading to an increase in production of TNF- $\alpha$ followed eventually by tissue damage.

Tramadol withdrawal of therapeutic dose and overdose in male rats causes a significant decrease in serum IL- $1 \mathrm{~B}$ while a non-significant decrease in serum TNF- $\alpha$ and brain tissue NF-KB concentrations compared with therapeutic dose and overdose groups. The effects of tramadol and tramadol withdrawal on inflammatory cytokines need further investigation. The effects of tramadol abuse and tramadol recovery on inflammatory cytokines need further investigation. The recorded data of present study showed a significant increase in brain tissue MPO activity in tramadol overdose group while there was a nonsignificant increase in the therapeutic dose group when compared with the normal control group. Myeloperoxidase is an essential enzyme for normal neutrophil function, released into extracellular fluid as a response to various stimulatory substances. These results are nearly similar to those recorded by Aldiwan et al., (2015) who reported that, the total leukocyte counts were significantly elevated in 50 $\mathrm{mg}$ and $100 \mathrm{mg} / \mathrm{kg}$ body weight tramadol treated groups. Also, Tsai and Won, (2001) showed that, tramadol administration causes an increase in number of lymphocytes in rats. Furthermore, Elyas and Osman, (2017) demonstrated that, tramadol abuse in individual causes elevated in white blood cell count. Myeloperoxidase activity is considered as an index for the evaluation of neutrophil infiltration. In the present study, the elevated activity of MPO in the brain tissue indicates oxidative injury induced by tramadol involves the contribution of neutrophil accumulation. Neutrophil enzyme MPO catalyzes formation of potent cytotoxic oxidants such as $\mathrm{HOCl}$ from $\mathrm{H}_{2} \mathrm{O}_{2}$ and chloride ions and $\mathrm{N}$ chloramines. Excessive production of MPO-derived oxidants has been linked to tissue damage in many diseases, especially those characterized by acute or chronic inflammation. The oxidants play a direct role in the inflammatory process in chronic inflammatory processes by increasing the number of neutrophils and macrophages that induce a self-sustaining loop (Shiratora et al., (1989); van der Veen et al., (2009)). Tramadol withdrawal of therapeutic dose and overdose in male rats causes a non-significant decrease in brain tissue MPO activity when compared with therapeutic dose and overdose groups. Tramadol withdrawal may be prevented the accumulation of neutrophils in the brain tissues, thus dampening the toxic effects of ROMs released from these cells. The present study supported that tramadol recovery could also facilitate the healing process of brain and liver inflammation by limiting the injury caused by activated neutrophils and the resultant release of 
ROS. The results obtained in present study showed that a significant decrease in brain tissue GPX activity and GSH concentration in both tramadol therapeutic and overdose groups compared with the normal control group. These results came in accordance with the recorded data of Elwy and Tabl, (2014) who reported that, administration of tramadol for 30 days induced significant decrease in hepatic tissue SOD, CAT activities and GSH concentration as compared to control rats. Also, Nada et al., (2014) showed that, administration of tramadol for 30 days resulted in significantly decrease in GSH level compared to control group rats. Glutathione is an enzyme which prevents the generation of hydrogen peroxide and alkyl hydro peroxides in association with GSH and GSH reductase, as well as the generation of more harmful metabolites such as the hydroxyl radical (Parodi, 2007). In the present study, the significant decrease in brain GSH content and GPX activity which paralleled with an increase in MDA level may be attributed to the enhanced lipid peroxidation leading to tissue damage and failure of antioxidant defense mechanism. This assumption is supported by the work of Abdel-Zaher et al., (2011) who reported that, administration of tramadol to normal mice resulted in depletion of GPX and subsequent potentiating of lipid peroxidation in kidney cortical slices resulting in inhibition of protein synthesis, and mitochondrial damage. Similarly, Pan et al., (2008) recorded that, a significant increase in the MDA level and a decrease in the GPX level in tramadol-treated group when compared to the control. It was reported that MDA is widely accepted as a sensitive biomarker of lipid peroxidation. It is considered a useful measure of oxidative stress status. Also, GPX enzymes were found to contain a transition metal as a cofactor. The interaction of tramadol with metals of these enzymes may explain the observed inhibition in the activities of these enzymes (Ismail et al., 2010). A non- significant increase in brain tissue GPX activity and GSH concentration were observed in tramadol withdrawal therapeutic dose and overdose groups when compared with therapeutic dose and overdose groups. These results may be similar to the recorded data of Elwy and Tabl, (2014) who reported that, stopping of tramadol for 30 days causes significant increase in hepatic tissue SOD, CAT activities and GSH concentration as compared to control rats.

A significant down regulation of Cyp2E1 gene expression level in liver tissue was observed in tramadol therapeutic and overdose groups when compared with normal control group. The role of the liver in detoxification and drug metabolism has previously been identified. This function increases the risk of these organs to toxic injuries, thus, all drugs been associated with hepatotoxicity following the essential role of the liver in drug metabolism (Abdelraouf et al., 2015). The main metabolic pathway of $\mathrm{N}-$ and $\mathrm{O}$ demethylation and conjugation of $\mathrm{O}$ demethylated compounds have been previously described. Eleven metabolites have been identified, five from phase I (M1 to M5) and six from phase II (glucuronides and sulfates of M1, M4 and M5) reactions. Tramadol is also rapidly metabolized in animals than in man (Lintz et al., 1981). The enzyme P450 (CYP) 2D6 has been suggested to be responsible for catalyzing O-demethylation of tramadol to M1 metabolite as a result of the inhibition by quinidine (selective CYP2D6 inhibitor) (Subrahanyan et al., 2001). The enzyme P450 (CYP) 2D6 has been suggested to be responsible for catalyzing O-demethylation of tramadol to M1 metabolite as a result of the inhibition by quinidine (selective CYP2D6 inhibitor) (Subrahanyan et al., 2001). Variations in tramadol biotransformation have been seen in phenotypic populations which depend on the genotype of CYP2D6 (Abdel-Rahman et al., 2002). Who also, reported that, CYP2D6-mediated metabolite (M1) is to a 
lesser extent formed while a more pronounced production of non-CYP2D6 product (M2) is formed in subjects with one versus two functional alleles.

In present study, the down regulation of Cyp2E1 gene expression may be due to the increase in serum TNF- $\alpha$ and NF-KB in the inflammation have been shown to alter CYP450-mediated activity (Harbrecht et al., 2005).

Also, cytochrome p450 enzymes, which are phase I enzymes that detoxify toxic compounds, have long been known to produce ROS when uncoupled, particularly $\mathrm{H}_{2} \mathrm{O}_{2}$ and hydroxyl radicals (Imaoka et al., 2004). Cyp2E1, Cyp2C11, and Cyp7b are all known to have $\mathrm{NF}-\kappa \mathrm{B}$ promoter elements. Cyp2E1 and Cyp2C11 are both down-regulated by pro-inflammatory cytokines (Morgan et al., (2002); AbdelRazzak et al., (2004)). A significant up regulation in the expression level of the brain tissue CYP2E1gene was noticed in tramadol withdrawal of therapeutic dose and overdose groups compared with tramadol therapeutic dose and overdose rats groups. In the present study, this result was unclear and need more Future research to determine the effect of CYP2E1 in tramadol abuse.

\section{CONCULSION}

The present study demonstrated that, tramadol administration induced kidney dysfunction, brain injury and oxidative stress in rats as well as degenerating endogenous antioxidant defense system mechanisms. Tramadol exposure caused significant increase in serum urea, creatinine, sialic acid, interleukin-1 $\beta$ (IL$1 \beta$ ) and tumor necrosis factor-alpha (TNF$\alpha)$ and brain tissue nuclear factor kappa $\mathrm{B}$ (NF-kB), myeloperoxidase (MPO). While, markedly decrease in brain tissue glutathione peroxidase (GPX), reduced glutathione, (GSH) also gene expression of CYP 450 2E1 in rat liver tissue both at the recommended dosage and the high dosage ranges. These findings are of importance to be considered in the patients who use tramadol as a pain killer especially in the long term condition.

\section{REFERENCES}

Abdel-Rahman, S.M., Leeder, J.S., Wilson, J.T., 2002. Concordance between tramadol and dextromethorphanparent/ metabolite ratios: the influence ofCYP2D6 and nonCYP2D6 pathways on biotransformation. J Clin Pharmacol 42(1), 24-29.

Abdelraouf, A.E., Noor, E.S., Hend, N.E., Ikram, M.H., 2015. TramadolInducedLiver and Kidney Toxicity among Abuserein Gaza Strip, Palestine. JJBS 8(2), 133-137.

Abdel-Razzak, Z., Garlatti, M., Aggerbeck, M., Barouki, R., 2004. Determination of interleukin-4-responsive region in the human cytochrome P450 2E1 gene promoter. Biochem Pharmacol 68, 1371-1381.

Abdel-Zaher, A.O., Abdel-Rahman, M.S., ELwasei, F.M., 2011. Protective effect of Nigella sativa oil against tramadol-induced tolerance and dependence in mice: Role of nitric oxide and oxidative stress. Neuro Toxicol 32, 725-733.

Aldalou, A.R., Abdel-Aziz, I., Shahwan, O., 2014. Impact of giving sildenafil (Viagra) / Tramadol (Tramal) combination on the blood of domestic rabbits. J Sci 4(3), 162-169.

Aldiwan, M.A., Alzobidy, A.M., Younis, M.A., 2015. The effect of Tramadol on some blood and biochemical parameters of male rats (Rattus norvegicus). Baghdad Sci J 12(3), 496-502.

Anbar, M., Neta, P., 1967. The production and use of F-18 labelled organic compounds. Int $\mathbf{J}$ Appl Rad Isot 18, 495-523.

Atici, S., Cinel, I., Cinel, L., Doruk, N., Eskandari, G., Oral, U., 2005. Liver and kidney toxicity in chronic use of opioids: An experimental long term 
treatment model. J Biosci 30(2), 245252.

Bekjarovski, N., Chaparoska, D., Radulovikj-Bekjarovska, S., 2012. Seizures after use and abuse of tramadol. Prilozi 33, 313-318.

Beyaert, R., Fiers, W., 1998. Tumor Necrosis Factor and Lymphotoxin. In: Cytokines, ARMS. a. R. Thorpe, (eds). San Diego: Academic Press; p.335-360.

Bloms-Funke, P., Dremencov, E., Cremers, T.I., Tzschentke, T.M., 2011. Tramadol increases extracellular levels of serotonin and noradrenaline as measured by in vivo microdialysis in the ventral hippocampus of freelymoving rats. Neurosci Lett 490(3), 191-195.

Brzozowski, T., Kwiecien, S., Konturek, P.C., Konturek, S.J., Mitis-Musiol, M., Duda, A., Bielański, W., Hahn, E.G., 2001. Comparison of nitric oxide-releasing NSAID and vitamin $\mathrm{C}$ with classic NSAID in healing of chronic gastric ulcers. involvement of reactive oxygen species. Med Sci Monit 7(4), 592-599.

DeLeo, J.A., Rutkowski, M.D., Stalder A.K., Campbell I.L., 2000. Transgenic expression of TNF by astrocytes increases mechanical allodynia in a mouse neuropathy model. Neuroreport 11, 599-602.

Dey, A., Cederbaum, A.I., 2006. Alcohol and Oxidative Liver Injury. Hepatology 43(2), 563-574.

Dickman, A., 2007. Tramadol: a review of this atypical opioid. Eur $\mathrm{J}$ Palliat Care 14, 181-185.

Drug and Therapeutics Bulletin at 40 . 2002. Drug Ther Bull 40(4), 25-6.

Eguchi, H., Ikeda, Y., Ookawara, T., Koyota, S., Fujiwara, N., Honke, K., Wang, P.G., Taniguchi, N., Suzuki, K., 2005. Modification of oligosaccharides by reactive oxygen species decreases sialyl lewis $\mathrm{x}$ mediated cell adhesion. Glycobiology 15, 1094-1101.
Elwy, A.M., Tabl, G., 2014. Effects of Chronic Usage of Tramadol, Acetaminophen and Tramacet on Some Biochemical and Immunological Changes in Male Rats. J Drug Res Egypt 35(1), 63-71.

Elyas, A.E., Osman, I.K., 2017. Hematological changes in drugs abusers attending to abdelaal elidresi psychiatric hospital. Eur J Pharm Sci 4(5), 19-24.

Feldmann, G., 2006. Liver apoptosis. Gastroenterol Clin Biol 30(4), 533545.

Gross, R.T., Bracci, R., Rudolph, N., Schroeder, E., Kochen, J.A., 1967. Hydrogen peroxide toxicity and detoxification in the erythrocytes of newborn infants. Blood 29, 481-493.

Hafez, E.M., Issa, S.Y., Abdel Rahman, S.M., 2015. Parenchymatous Toxicity of Tramadol: Histopathological and Biochemical Study. J Alcohol Drug Depend 3, 225.

Harbrecht, B.G., Frye, R.F., Zenati, M.S., Branch, R.A., Peitzman, A.B., 2005. Cytochrome P-450 activity is differentially altered inseverely injured patients. Crit Care Med 33(3), 541-546.

Hayden, M.S., Ghosh, S., 2011. NF-kappa B in immunobiology. Cell Res 21, 223-244.

Imaoka, S., Osada, M., Minamiyama, Y., Yukimura, T., Toyokuni, S., Takemura, S., Hiroi, T., Funae, Y., 2004. Role of phenobarbital inducible cytochrome $\mathrm{P} 450 \mathrm{~s}$ as a source of active oxygen species in DNA-oxidation. Cancer Lett 203, 117- 125.

Ismail, M., Al-Naqeep, G., Chan, K., 2010. Nigella sativa thymoquinonerichfraction greatly improves plasma antioxidant capacity and expres-sion of antioxidant genes in hypercholesterolemic rats. Free Radic Biol Med 48, 664-672. 
Kabel, L.S., Van Puijenbroek, E.P., 2005. Side effects of tramadol: 12 years of Experience in the Netherlands. Ned Tijdschr Geneeskd 149(14), 754-757.

Kaplan, L.A., Pesce, A.J., Kazmerczak, S.C., 2003. First MR: Renal Function. In: Kaplan, LA., Pesce, A., (eds). Clinical Chemistry: Theory, Analysis and Correlation. $4^{\text {th }}$ ed. St. Louis, MO., USA: Mosby Inc.; 567585.

Kawasaki, Y., Zhang, L., Cheng, J.K., Ji, R.R., 2008. Cytokine mechanisms of central sensitization: distinct and overlapping role of interleukin1beta, interleukin-6, and tumor necrosis factor-alpha in regulating synaptic and neuronal activity in the superficial spinal cord. J Neurosci 28, 5189-5194.

Konturek, P.C., Duda, A., Brzozowski, T., Konturek, S.J., Kwiecien, S., Drozdowicz, D., Pajdo, R., Meixner, H., Hahn, E.G., 2000. Activation of genes for superoxide dismutase, interleukin-1 $\beta$, tumor necrosis factora and intercellular adhesion molecule-1 during healing of ischemia - reperfusion gastric injury. Scand J Gastroenterol 35(5), 452463.

Li, J., Xie, W., Zhang, J.M., Baccei, M.L., 2009. Peripheral nerve injury sensitizes neonatal dorsal horn neurons to tumor necrosis factoralpha. Mol Pain 5, 10.

Lindenlaub, T., Sommer, C., 2003. Cytokines in sural nerve biopsies from inflammatory and noninflammatory neuropathies. Acta Neuropathol 105, 593-602.

Lintz, W., Erlacin, S., Frankus, E. 1981. Biotransformation of tramadol inman and animal [in German]. Arzneimittel Forschung 31(11), 1932-1943.

Liu, B., Li, H., Brull, S.J., Zhang, J.M., 2002. Increased sensitivity of sensory neurons to tumor necrosis factor alpha in rats with chronic compression of the lumbar ganglia. $\mathbf{J}$ Neurophysiol 88, 1393-1399.

Meadus, W.J., 2003. A semi- Quantitative RT-PCR method to measure the in vivo effect of dietary conjugated linoleic acid on protein muscle PPAR gene expression. Biol Proced 5(1), 20-28.

Meyer, R., Patel, A.M., Rattana, S.K., Quock, T.P., Mody, S.H., 2014. Prescription opioid abuse: a literature review of the clinical and economic burden in the United States. Popul Health Manag 17(6), 372-387.

Moratti, E., Kashanpour, H., Lombardelli, T., Maisto, M., 2010. Intravenous misuse of buprenorphine: characteristics and extent among patients undergoing drug maintenance therapy. Clin Drug Investig 30, 3-11.

Morgan, E.T., Li-Masters, T., Cheng, P.Y., 2002. Mechanisms of cytochrome $\mathrm{P} 450$ regulation by inflammatory mediators. Toxicology, 181-182, 207-210.

Moron, M.S., Depierre, J.W., Mannervik, B. 1979. Levels of glutathione, glutathione reductase and glutathione S-transferase activities in rat lung and liver. Biochimica et Biophysica ACTA 582, 67-78.

Nada, S.A., Eldenshary, E.S., Abdel Salam, O.M., Azmy, S.A., Mahdy, T., Galal, A.F., Omara, E.A., 2014. Grape Seed Extract attenuate Tramadol-Alcohol hepatotoxicity and increased antioxidant status in Sprague Dawley Rats. Cur Sci Int 3, 260- 270.

Nossaman, V.E., Ramadhyani, U., Kadowitz, P.J., Nossaman, B.D., 2010. Advances in perioperative pain management: Use of medications with dual analgesic mechanisms, tramadol \& tapentadol. Anesthesiol Clin 28, 647-666.

Ogasawara, Y., Namaia, T., Yoshinob, F., Leeb, M., Ishiia, K., 2007. Sialic acid is an essential moiety of mucin as a 
hydroxyl radical scavenger. FEBS Letters 581, 2473-2477.

Pahl, H.L., 1999. Activators and target genes of Rel/NF-kappaB transcription factors. Oncogene 18(49), 6853-6866.

Pan, H.Z., Zhang, H., Chang, D., Li, H., Sui, H., 2008. The change of oxidativestress products in diabetes mellitus and diabetic retinopathy. $\mathrm{Br}$ J Ophthalmol 92(4), 548-551.

Pang, W.W., Wu, H.S., Tung, C.C., 2003. Tramadol $2.5 \mathrm{mg}$ (middle dot) $\mathrm{kg}$ ${ }^{1}$ appears to be the optimal intraoperative loading dose before patient-controlled analgesia (French Article). Can J Anesth 50(1), 48-51.

Parodi, P.W., 2007. A role for milk proteins and their peptides in cancer prevention. Curr Pharm Des 13(8), 813-828.

Rafati, A., Yasini, S.M., DashtiRahmatabadi, M.H., Pakdel, S., Norani, F., 2006. Tramadol Dependence Rate as Compared with Morphine in Rats. World J Med Sci 1(1), 40-43.

Sacerdote, P., Bianchi, M., Gaspani, L., Manfredi, B., Maucione, A., Terno, G., Ammatuna, M., Panerai, A.E., 2000. The effects of tramadol and morphine on immune responses and pain after surgery in cancer patients. Anesth Analg 90(6), 1411-1414.

Sacerdote, P., Bianchi, M., Manfredi, B., Panerai, A.E., 1997. Efects of tramadol on immune responses and nociceptive thresholds in mice. Pain 72, 325-330.

Shadnia, S., Soltaninejad, K., Heydari, K., Sasanian, G., Abdollahi, M., 2008. Tramadol intoxication: a review of 114 cases. Hum Exp Toxicol 27, 201-205.

Shiratora, Y., Aoki, S., Takada, H., Kiriyama, H., Ohto, K., Hai, K., Teraoka, H., Matano, S., Matsumoto, K., Kamii, K., 1989. Oxygen-derived free radical generating capacity of polymorphonuclear cells in patients with ulcerative colitis. Digestion 44(3), 163-171.

Stitik, T.P., Altschuler, E., Foye, P.M., 2006. Pharmacotherapy of osteoarthritis. Am J Phys Med Rehabil 85(Suppl 11), S15-28.

Subrahanyan, V., Renwick, A.B., Walters, D.G., 2001. Identification ofcytochrome P-450 isoforms responsible forcis-tramadol metabolism in human livermicrosomes. Drug Metab Dispos 29(8), 1146-1155.

Tietz, N.W., 1995. Clinical Guide to Laboratory Tests. $3^{\text {rd }}$ ed. Philadolphia, USA: Sauders W.B.

Tsai, Y.C., Won, S.J., 2001. Effects of tramadol on $\mathrm{T}$ lymphocyte proliferation and natural killer cell activity in rats with sciatic constriction injury. Pain 92, 63-69.

van der Veen, B.S., de Winther, M.P., Heeringa, P., 2009. Myeloperoxidase: molecular mechanisms of action and their relevance to human health and disease. Antioxid Redox Signal 11, 2899-2937.

Wilder-Smith, C.H., Hill, L., Osler, W., Okeefe, S., 1999. Effect of tramadol and morphine on pain and gastrointestinal motor function in patients with chronic pancreatitis, Digestive Dis Sci 44, 1107-1116.

Yamamoto, Y., Gaynor, R.B., 2001. Therapeutic potential of inhibition of the NF-kappaB pathway in the treatment of inflammation and cancer. J Clin Invest 107(2), 135142.

Youssef, S.H., Zidan, A.H., 2016. Histopathological and Biochemical Effects of Acute and Chronic Tramadol Drug Toxicity on Liver, Kidney and Testicular Function in Adult Male Albino Rats. J Med Toxicol Clin Forensic Med 1, 2-7. 